\title{
The Study on the Characters and the Pattern of Educational Promotion of Japanese Specialized Professional Institute
}

\author{
Qifeng Zou ${ }^{1, a^{*}}$, Hairu Yang ${ }^{2, b}$ \\ ${ }^{1}$ Col. of Humanities, university of Macau, 999078, Macau, China \\ 2 Japanese Department of Jiaxing University, 314001, Zhejiang, China \\ azouqifeng@126.com, ${ }^{\mathrm{b}} 1556496787 @ q q . c o m$
}

Keywords: Specialized professional institute (SPI); Ministry of education; Science and culture; Classification; Pattern of educational promotion

\begin{abstract}
With high level and high standard, Japanese vocational education has advanced to the level of Specialized Professional Institute (SPI). The setup of Japanese SPI is not only to meet the needs of highly developed Japanese economic and society for high science and technology, high skilled professional people, but also to meet the needs of higher vocational college graduates for entering to a higher level of specialized education, and to meet the need of the national Japanese receiving lifelong education, especially the lifelong vocational education. And the setup of Japanese SPI has the strictness of formulation and the flexibility to perform in the aspects of professional settings, curriculum requirements, internship and practical training and educational system length of schooling. Moreover, the pattern of educational promotion proves to be constructive in the field of vocational education. In this circumstance, it is vital important to analyze the characteristics of SPI and the pattern of educational promotion, to find out its operating advantages and features, so as to offer enlightenment for the growth of Chinese vocational education.
\end{abstract}

\section{Introduction}

In order to improve the level of vocational and technical education, our country has introduced in a series of reform policies in the last ten years. Among them, school-enterprise cooperation and work study combination policy are catching the most attentions and is the most noticeable. The purpose is to increase the chance of developing students' practical training and to improve the actual professional quality, so as to realize the smooth connection between students and careers after their graduation. Practical training of vocational ability is admittedly important, however, with the continuous development of economic and social development, greater demands are placed by those who accept vocational education as they also need higher quality status and educational level. Simply training of vocational technology cannot meet their needs any more. Nowadays, students in vocational colleges anticipate, on the one hand, obtaining the corresponding professional quality, on the other hand, possessing the qualification of continuing higher level of education during the period of school education. Therefore, problems of entering higher school of vocational college students have become a prominent topic. In western, those countries which launch longer time of vocational education development have perfected the system of vocational education and the setup of entering a higher education system on the basis of their national conditions. On the one side, they are able to meet the needs of the economic and social development of high level skilled personnel, on the other side; they are capable of satisfying and meeting the needs of higher education proposed by those vocational education educators.

In China so far, the vocational education has been developed, but comparatively the corresponding vocational education entrance system is still in stage. Therefore, there is a vital necessity to take full consideration of the national conditions of our country, to learn from the mature experience of foreign countries, and to gradually improve the entrance system of vocational college graduates in China. The system needs to expand the proportion and scale of vocational college graduates receiving higher levels of education, needs to reform the existing examination system, and needs to build a practical system capable of smoothly integrating vocational education 
and general education, which indeed makes vocational education dynamically integrate into China's overall national education system, instead of being an individual independent from other national education sectors. It therefore, can be used as a means of training the talents with specialized knowledge and skills, and can become an important way to improve the level of education of the education receivers.

In today's vocational colleges in China, students who receive vocational education can only get a three-year college degree; they can complete four-year degree at most, which is far from meeting the educational requirements of the education receivers. By contrast, in the neighboring Japan, full categories and complete majors of Specialized Professional Institute (SPI) have been matured, and students graduating from SPI are eligible for masters and doctoral degrees of special vocational professionals.

\section{The Originality of Japanese Specialized Professional Institute (SPI)}

Japan is not only a country with frequent visit of tsunami, volcanic eruptions and other natural disasters, but also a country with acute shortage of oil, copper, nickel, iron ore and other industrial resources. Meanwhile it is a country with great natural beauty, being one of the world's major tourist countries. The industry is well developed, and in 1969 the first gross domestic product (GDP) surpassed the Federal Republic of Germany at that time and the Soviet Union one of the "superpowers", and become the world's second largest economy second only to the United States, and had topped the throne of 42 years, until China held the lead position by a tiny margin in 2010 . Although Japan is clearly insufficient in the material resources, it holds the dominant position in the aspect of human resources, education resources, especially in the specialized professional human resources and is much far richer than any other countries. With the characteristics of Japanese economy being well developed, the level of application of science and technology was put in the same league as the West. Owning to the advanced medical level, the life expectancy of men and women being the longest among the world, and the problem of Aging Population with too Few Children are the cause of higher technical requirements to professional people with expertise, specialized professional career, and skilled craftsmen, taking clinical psychologists as an example. All these are not just empty talk theory or academic talents can provide. In order to provide a more intimate and more personalized professional services to the aged people in the aging Japan society, and to provide such as professional legal consultation service to a specific field, all require professional knowledge and professional skills which being set under the specific circumstance of such Japanese economic, cultural and social needs. Therefore, Japan's Specialized Professional Institute (SPI) came into being. The degree issued by SPI also up-shift to the Japanese professional Master degree (also known as the Professional Master), Professional Doctor (or annotates vocational after the Professional Doctor), such as Master of Social Service Management (Professional).

\section{Character Analysis of Japanese Specialized Professional Institute (SPI)}

Japan's graduate school is to some extent sharing some similarities with China's graduate school, but SPI is quite different from the graduate schools of general universities in China no matter on the form or content. Meanwhile, it is different from the general Japanese graduate school. According to Item 4 of Article 54 of Japan's School Education Law: 専門職大学院（せんもんしょくだいがく (ん）とは、「大学院のうち、学術の理論及び応用を教授研究し、高度の専門性が求めら れる職業を担うための深い学識及び卓越した能力を培うことを目的とするもの」のことで ある。[1] (SPI is set up on the purpose of instructing and doing research on the academic theory and application, training the remarkable capability and profound knowledge for highly specified careers.) Japanese School Education emphasizes the attribute of both the theory and the application of SPI, and the characteristic of remarkable capability of high-level specialization and professional requirements. According to the school properties of SPI, it can be divided into national, public and 
private SPI. According to the speciality classification of SPI, it can be divided into Technical Management, Accounting, Public Policy, Public Health, Clinical Psychology, Nursing, Welfare, Art, Home Economics and Legal Science and so on. Majors Japanese SPI have set up almost cover all the majority of general colleges and universities have apart from military professional. The national and public SPI, in addition to the educational regulations of Japanese Ministry of Education, Science and Culture, are under the check and supervision of the boards of education and detailed-rules of various prefectures. Whether it is a national, public or private SPI, its professional settings, teacher allocation and the entrance of SPI graduates, despite taking the level of economic and social development, population size and regional distribution into account, the most important is that considering the demand conditions produced by the economic development to various professional and highly skilled personnel, and emphasizing on the coordinating development of theory teaching and practical skills, degree education and non-degree education, vocational education and general education, and with the condition of the effective convergence of pre-service education and post-service education. Only in this way can the situation meet the needs of the Japanese people accepting a high level, high standard specialized vocational education, satisfy the needs of the Japanese economic and social development in wanting of high-quality professional, and skilled personnel.

Japanese SPI are normally autonomous enrollment, without any uniformed examinations held by the nation or prefecture boards of education. The school board, academic committee and other educational institutions are responsible for teaching management, academic research and other daily work on the aspect of the operation and management of each SPI. The fundamental difference between the Japanese SPI and the general universities is that the general college and university are focusing on the training of researchers, and the SPI are intend to cultivate high-level substantive staffs who are equipped with professional knowledge, professional skills and professional ethics in the field of professional practice for the purpose of teaching and practice.[2] Its selection and appointment standards of curriculum system, curriculum structure, teaching staff are clearly defined, the detailed requirements are clearly put forward to the school students, and requirement details are came up with the graduate school students for the course election and degree awarding. The Japanese SPI, in addition to the clear-cut distinction of various major categories, even in the same specialized subject, can be divided into different majors according to the differences of research directions and different professions have clear and explicit different requirements of degree awarding. Therefore, it is absolutely possible to obtain a double-degree degree with different majors in the same direction in SPI in Japan. Due to the purpose of SPI is to foster practitioners with a high degree of professional knowledge, and a high level of professional skills, the students of it may have been in-service staffs or working staffs. For such kind of audient community, if the school has no time convenience, these minority groups may lose opportunities of accepting highly specialized vocational education. As a consequence, the classification of Japanese SPI, apart from the differences among various major categories, prefectures these schools located and the property distinctions of national, public or private institutes of the enrollment institutions, lies on the difference between lecture forms of the education courses. It not only has the full-time schooling form as the general universities and colleges, but also includes various forms as lectures during the day only, lectures at night only, or adopt means of communication or remote online education.

According to the broad professional categories, the classifications of SPI in Japan can be divided into Education Specialized Professional Institute, Law Specialized Professional Institute, Accounting Specialized Professional Institute, and Clinical Psychology Specialized Professional Institute and so on. There into, Law Specialized Professional Institute and Education Specialized Professional Institute are different from other professional categories of Graduate School. As to these two SPIs, Japanese Ministry of Education, Culture, Sports, Science and Technology(MEXT) has set out specific standards at the aspects of their professional settings, curriculum requirements, names of academic degrees awarding and so on. After the war, the training of teachers in Japan was carried out within teacher training institutions which mainly consist of universities and colleges, and including junior colleges. With the development of Japanese economy, society and culture, the 
requirements for teachers' professional knowledge, education level and professional ethics are calling for increasingly higher demand. In order to catch up with the fast-changing requirements, the Central Educational Discussion of Japanese MEXT held Topic Symposia, and finally made the decision that the cultivation of the teachers should be carried out by specialized colleges. Japan's Education Specialized Graduate School was first founded in April 1st, 2008.

According to the report 2013 Annual Education Specialized Professional Institute issued by the National Agency for Higher Education's University Revitalization and Science and Education Staff Training Office which is a branch of MEXT, among the 47 prefectures(To, Do, Fu, Ken in Japanese), there are 6 private graduate schools including Soka University Graduate School, Tamagawa University Graduate School, Waseda University Graduate School, Teikyo University Graduate School etc. having the capacity for enrolling 170 students. Besides, there are 19 national graduate schools including Hokkaido University of Education Graduate School, Miyagi University of Education Graduate School, Gifu University Graduate School, Aichi University of Education Graduate School, and Nagasaki University Graduate School etc. having the capacity for enrolling 645 students. So far, there is no public university setting up Education Specialized Professional Institute, in 2014 there is no new increase, therefore, in Japan, currently there are 25 national, private Education Specialized Professional Institute in total, and the geographical range encompasses regions of Hokkaido, the northeast, Kanto, the central region, and Kinki Kinki region, until Kyushu (Kyushu) and Okinawa (Okinawa) which are the outlying Islands. The enrollment quota is based on the region's economic and social development level and demand conditions of education team. [3]

The setting up of Japanese Law Specialized Professional Institute is on the purpose of dealing with the constant improvement of national legal consciousness, the increasing legal advice needs to multi aspects and multi levels of national economic and social life, and elevated requirements to the quality of judicial officers and lawyers. On the one hand, the legal profession and legal education set up by SPI deliver qualified personnel with legal literacy for all sectors of society; on the other hand, in Japan, the phenomenon that students do not go to college or university, directly enter the specialized prep schools which is proficient in exams also exists. And some of these people have entered the Department of Justice through the judicial examination or have set up their own law firms. [4] In this case, the passing of Judicial Examination can not guarantee the competent aptitude or ethical conduct as the judicial officers or lawyers. The complete set of organic combinations of law education, judicial examination and judicial practice ensures the systematic protection of cultivating qualified legal personnel, and Law Specialized Professional Institute is in this environment was emerged under such social and economic environment. In April 2004, Law Specialized Professional Institutes were set up. The Japanese MEXT carried out specialized adaptability test for these enrollees, and only after passing this test and being qualified can they be eligible to take the admission test selection held by Law Specialized Professional Institutes, and accept the practical training education specialized for students who will work in justice departments. MEXT clearly stipulated in writing about curriculum construction of registered Law SPI students that include the legal basis course group, the practice basis course group, the basic law course with related subject course group and frontier development course group. And furthermore, each Law Specialized Professional Institute only has the right of discretion of the credit of each course group. The curriculum, teachers' teaching and researching status within five years must be reviewed by specialized assessment and certification authorities, and by all means can every SPI make self-determination to choose from several coexistent authentication and evaluation organizations. These coexistent authentication and evaluation organizations include Japan University Accreditation Association, National Institution for Academic Degrees and University Evaluation, Public Welfare Foundation and Japanese Lawyer Association of Legal Research Financial Group and so on. For the requirements of completion, degree awarding and so on of the students in Law SPI, MEXT has already worked out clear regulations.

In a conclusion, the classification of Japanese SPI can launch according to the general professional categories, also can be set up according to the attributes of the Graduate Schools of the 
universities, or in accordance with Japan's 47 Prefectural Administrative Divisions SPI located in, and can also be classified according to the teaching schedules. While in the classifications of the general professional categories, Education Specialized Professional Institutes and Law Specialized Professional Institutes are distinguished from other professions of Specialized Professional Institutes from the aspects of curriculum arrangement, course group formulation, degree completion, degree awarding as MEXT having already worked out clear and direct regulations for them. Comparatively, other SPIs have more rights of discretion on broader aspects.

\section{The Analysis of the Pattern of Educational Promotion of Japanese Specialized Professional Institute}

The Significance of the Educational Promotion and Degree Awarding of SPI. Japan holds the oral defenses organized by the special specialized degree evaluation committee to students who make an application of degree with the preconditions of having finished the complete section of study in SPI, obtained the minimum credits and internship and practical training and practice requirements. And the qualified students can obtain the degree of SPI. This in a certain extent reflects that the MEXT and Japanese society have already generally agreed on the important position and role of the Japan SPI in Japan's economic and social life. Japan has already entered the aging society, coupled with the phenomenon of sharp drop in the birthrate, therefore, they need the whole society pay great attention on the aged in particular, caring for their physical and mental development, caring for the widowed aged, empty nesters. In such environment, the society requires highly qualified and specialized professional nursing people, rather than the nursing staffs only knowing how to give or take an injection or giving an intravenous drip. The psychological consultation, skill development, and investment and financing of the aged people need to have the high degree of professionals qualified with professional knowledge, expertise, and professional ethics to provide professional, thoughtful, personalized service. So it can be seen in chart 2 that, the famous national universities Kyoto University and Kyushu University have also founded SPI and award the qualified students the degrees of Master of Public Health(professional degree), Master of Public Health(professional degree). Above mentioned is only about several related professional careers hastened by the Japanese aging population with too few children society. As a matter of fact, since Meiji Restoration, Japan stepped on into the orbit of the development of capitalist economy, and even from 1969, it climbed atop to the world's second largest economy as long as 42 years. Japan is already an economic and cultural highly developed social body, and in every aspect of economy, culture and life, it needs highly specialized, highly professionalized professional people and master hands in all walks of life. The degree awarding of SPI is a reflection of the needs of professional practitioners of Japanese economy and society and the recognition of the approval up-shift degree of SPI given by MEXT. And the move in a certain extent can promote the benign development of SPI in Japan, making a contribution to better the development of Japanese society.

The Pattern of Educational Promotion of Japanese Specialized Professional Institute. Due to the various classification methods of SPI, the patterns of educational promotion are also widely divergent. According to the kinds of professional category, SPI can be divided as legal SPI, education SPI, public policy SPI, medical and public health SPI, and clinical psychology practice SPI. The paper mentioned above that Education SPI and Law SPI are distinguished from other professions of SPI from the aspects of curriculum arrangement, course group formulation, and educational promotion as MEXT having already worked out clear and direct regulations for them. Therefore, in the official website, students can consult its related admission requirements to complete their educational promotion application. In addition to the law and education SPI, the patterns of other professions of Specialized Professional Institutes are significantly differentiated. The following will take the examples of clinical psychology practice SPI and science technology SPI to illustrate their educational promotion patterns.

On the educational promotion of clinical psychology practice SPI and science technology SPI, it is focusing on the graduating college students of medical professional, social service professional, public policy and science technology professional as the main object of enrollment. Besides, for 
those who are business administration major already in the workforce and seeking to learn highly specialized knowledge and the newest knowledge and technology, and those who have already had the professional practice experience and hope to improve the professional knowledge, they can also participate in the course of full-time or night lecture lasts for two years and the qualified can be eligible to get a degree. Entering to clinical psychology practice SPI and science technology SPI, the graduating college students mentioned above and students who major in other professionals but are committed to work and research in this field can apply for admission to. When holding the entrance examination, in addition to the written examination of professional courses, there is also the interview centered on the paper of the field related topics as well as the AO entry system which estimates the students' learning will, learning ability and so on. The AO entry system means that a selection method when in the educational promotion, used to synthetically judge other abilities apart from the test results of subjects, such as adaptability, self-learning ability, learning interest and learning desire. For the educational promotion of foreigners or in-service staffs, the SPI has also set up other conditions, such as a fixed number of years of practical experience and minimum academic requirements as well as the requirements of foreign language ability foreign students should meet.[5] Although the educational promotion patterns mentioned above are suitable for clinical psychology practice SPI and science technology SPI, for other professionals, expect the professional difference, it shares several commonalities in other aspects of requirements, such as study will, the adaptability of the environment, the writing level of the professional paper, or the minimum educational requirement.

The Requirements and Types of Degree Awarding of Japanese Specialized Professional Institute. Just as the bachelor's degree, master's and doctoral degree in Chinese, Japan's SPI also has corresponding classification of degrees, awarding requirements and types of degree, as well as the corresponding professional qualification certificate for professional people. The degree awarding is at the level of graduate school; therefore, the degree is limited to master and doctor's degree. As SPI is different from that of ordinary graduate schools, in degree awarding, Japanese MEXT sets out special clear rules and requirements on the name of the degree. Generally, the Japanese graduate schools set two-year curriculum for master's degree. And after achieving the master's degree, students can select three-year curriculum for doctor's degree. They can obtain the doctoral degree with required credits and fulfilling the degree awarding requirements of academic dissertation, experimental design, internship and practical training. But some graduate schools in Japan also call the curriculum for master's degree as pre-doctoral or pre-two-year doctoral programs, which can not be awarded a doctoral degree, in line with the degree is awarded only as master's degree.

Considering the factors of international generality and academic age limit, Central Council for Education which belongs to Japanese MEXT made the provisions of the corresponding degree awarding of SPI in April, 2002: to add parentheses between the degree professional category, and be bound to give clear indication of the professional degree like master/doctor of practice, or professional master/doctor before or after the degree, in order to make a difference to the general degree. If SPI is in the same professional and same master's degree as general university or college, such as the professional of computer science, in principle, the degree of SPI should put Master of Practice (computer science professional), or Master of Specialized Professional (computer science professional), or be marked as master of computer science (professional degree) as well. If SPI is in the same professional and same doctor's degree as general university or college, such as the professional of law, in principle, the degree of SPI should put Doctor of Practice(law professional)or Doctor of Specialized Professional (law professional), or be marked as Juris Doctor(professional degree) as well. The other professionals are also following this regulation. The degree classification of Japanese SPI is shown in chart 1, the name of degree of other SPI professionals follow other specific provisions, comparatively, the Law SPI and Education SPI follows the related express provisions made by MEXT on their curriculum standards and requirements of degree awarding to differentiate from other SPI. The general degree classification of SPI except law and education professionals is listed in chart 2. 
Chart 1 the Degree Classification of Japanese SPI

\begin{tabular}{|c|l|l|}
\hline $\begin{array}{c}\text { Broad Division } \\
\text { Degree }\end{array}$ & $\begin{array}{l}\text { Small Division } \\
\text { Juris Doctor (professional degree) } \\
\text { or Doctor of Practice(law } \\
\text { professional) }\end{array}$ & $\begin{array}{l}\text { Standard of Degree Awarding } \\
\text { Institute }\end{array}$ \\
\hline $\begin{array}{c}\text { Professional } \\
\text { Degree }\end{array}$ & $\begin{array}{l}\text { Master of Education (professional Professional } \\
\text { degree) or Master of Specialized } \\
\text { Professional (education } \\
\text { professional) }\end{array}$ & $\begin{array}{l}\text { Education Specialized } \\
\text { Professional Institute }\end{array}$ \\
\hline $\begin{array}{c}\text { Professional } \\
\text { Degree }\end{array}$ & Master (professional degree) & $\begin{array}{l}\text { Specialized Professional } \\
\text { Institute(except Law and } \\
\text { Education professional) }\end{array}$ \\
\hline
\end{tabular}

These charts consult the related provisions of Japanese Education Law

In chart, the Law SPI and Education SPI refer to the related express provisions made by MEXT on their curriculum standards and requirements of degree awarding

Specialized Professional Institute refers to the specific conditions and requirements of degree awarding universities.

Chart 2 Degree of SPI and Representative Universities(except Law and Education professional)

\begin{tabular}{|c|c|c|}
\hline Broad Division & Small Division & Grantor \\
\hline $\begin{array}{l}\text { Professional } \\
\text { Degree }\end{array}$ & Master of Public Health & Kyushu University \\
\hline $\begin{array}{l}\text { Professional } \\
\text { Degree }\end{array}$ & Master of Accounting \& Finance & $\begin{array}{l}\text { Chiba University of } \\
\text { Commerce }\end{array}$ \\
\hline $\begin{array}{l}\text { Professional } \\
\text { Degree }\end{array}$ & Master of Public Policy & Hitotsubashi University \\
\hline $\begin{array}{l}\text { Professional } \\
\text { Degree }\end{array}$ & Master of Public Policy & Tohoku University \\
\hline $\begin{array}{l}\text { Professional } \\
\text { Degree }\end{array}$ & $\begin{array}{l}\text { Master of Business Administration in } \\
\text { International Accounting }\end{array}$ & Center University \\
\hline $\begin{array}{l}\text { Professional } \\
\text { Degree }\end{array}$ & $\begin{array}{l}\text { Master of International \& Administration } \\
\text { Policy }\end{array}$ & Hitotsubashi University \\
\hline $\begin{array}{l}\text { Professional } \\
\text { Degree }\end{array}$ & $\begin{array}{l}\text { Master of Business information technology } \\
\text { (MBIT)/Master of Science in Information } \\
\text { Technology (M.S.in IT) }\end{array}$ & $\begin{array}{l}\text { Hosei University, } \\
\text { The Kyoto College of } \\
\text { Graduate Studies for } \\
\text { Informatics }\end{array}$ \\
\hline $\begin{array}{l}\text { Professional } \\
\text { Degree }\end{array}$ & $\begin{array}{l}\text { Master of Science in Information Systems } \\
\text { (M.S.in IS) }\end{array}$ & $\begin{array}{c}\text { Kobe Institute of Computing; } \\
\text { Graduate School of } \\
\text { Information Technology }\end{array}$ \\
\hline $\begin{array}{l}\text { Professional } \\
\text { Degree }\end{array}$ & Master of System Safety & $\begin{array}{l}\text { Nagaoka University of } \\
\text { Technology }\end{array}$ \\
\hline $\begin{array}{l}\text { Professional } \\
\text { Degree }\end{array}$ & Master of Public Health & Kyoto University \\
\hline $\begin{array}{l}\text { Professional } \\
\text { Degree }\end{array}$ & Master of Business Administration & Waseda University \\
\hline
\end{tabular}

This chart is selecting part of corresponding types of degree and the degree awarding Professional Graduate School according to the list issued by Japanese MEXT in July2014. 


\section{The Enlightenment of Japan's Specialized Vocational College on the Vocational Education in China}

The setup of Japanese Professional Graduate School and the degree awarding of the qualified graduates provide experiences and references on the development of Chinese professional education.

On the one hand, students obtaining degree from Japanese Specialized Professional Institute play the role of professional people from all walks of economic and society life. Based on their excellent professional skills acquired in SPI, they can create great value for the society at the same time can fully display their personal value. China and Japan are essentially in balance from the aspect of gross market economy. According to the official website of the Ministry of Education of the People's Republic of China, in 2013, the number of graduate students entering the job market is 6990000 , and in 2014 reached a new record of 7270000 . Comparatively, due to the social reality of aging population with too few children in Japan, the number of graduate students is just 500000, only one over fifteen of China. However, depending on that amount of occupational groups, on their vocational skills trained in Professional Graduate School, they have already been capable of basically meeting the economic and social needs and creating the economic value consistent with China. Therefore, it can be seen that Japan's professional education model based on Professional Graduate School is very successful.

On the other hand, the academic level of degree students obtained from Japan's Specialized Professional Institute, especially the professional integrity cultivated in the form of successful education model are no less than Japanese general university or college graduates, and even with more advantages. In recent years, in Chinese human resources market, some employers have offered a lot of enviable preferential treatment to employees, but few people can successfully apply the position, which may be affected by the economic environment. But at the same time, this situation reflects that the professional skills, knowledge level, academic level and professional ethics of our country's vocational school graduates can not meet the needs of China's market development. The vocational education in Japan has obvious advantages compared to the vocational education in China as Chinese vocational education is limited in the model of Junior College and Undergraduate College/University. The system in Japan has trained professional people who specialize in professional knowledge and professional skills and has a high degree and high professional ethics, and has gained universal praise in all walks of life. This also shows that Japan's highly specialized professional education based on SPI provides suitable talents for Japan's economic and social development. This shows that Japanese SPI provide a useful inspiration for our vocational education, no matter in the contents, methods or pattern of educational promotion.

\section{References}

[1] Japanese MEXT official website: http://www.mext.go.jp/ 2014.8.13.

[2] Moriki Terada. The present situation of Japanese talent training from the perspective of vocational education [J]. Essentials of Graduate School in Nagoya university, 2011.(11):89-94.

[3] Koichi Hashimoto. Vocational Education in Japan [M].Yuchuan University Press, 2009:76.

[4] Horiuchi T, Katsuo I, Fumito Setal. Vocational Education in Japan and cross the World [M].Legal Culture Press, 2013: 165.

[5] Zhu Wei. The influence of economic powers_ the perspective of Japanese Education [J]. Primary and Secondary School Education Abroad, 2000(06)

[6] Peng MingXin. The amendment of Fundamental Law in Education and Transformation of Basic concept in Education. [D]. Northeast Normal University, 2006.

[7] Ning Xianfu Hua Dan. Dual Characters: The Influence of Japanese Culture to Education[J]. Journal of Technology College Education, 2010(06) 
[8] Zhou Yi. The School Pattern of Vocational Education in Japan [J]. Journal of Chongqing Vocational and Technical College, 2002(01)

[9] Wang Fengying. Develpoed Vocational Education in Japan [J]. Talent and Employment, 2003(16)

[10]Wang Shuai, Gong Xiaowei. Changes of School Pattern of Post-war Japanese vocational education. Chinese nation education, 2007(Z1) 